Kansas State University Libraries

New Prairie Press

\title{
SEPARATION OF SINGLE GENE EFFECTS FROM ADDITIVE- DOMINANCE GENETIC MODELS
}

Jixiang $\mathrm{Wu}$

Johnie N. Jenkins

Jack McCarty Jr

Chris Cheatham

See next page for additional authors

Follow this and additional works at: https://newprairiepress.org/agstatconference

Part of the Agriculture Commons, and the Applied Statistics Commons

\section{(c) (1) $\Theta($}

This work is licensed under a Creative Commons Attribution-Noncommercial-No Derivative Works 4.0 License.

\section{Recommended Citation}

Wu, Jixiang; Jenkins, Johnie N.; McCarty, Jack Jr; and Cheatham, Chris (2000). "SEPARATION OF SINGLE GENE EFFECTS FROM ADDITIVE-DOMINANCE GENETIC MODELS," Conference on Applied Statistics in Agriculture. https://doi.org/10.4148/2475-7772.1254

This is brought to you for free and open access by the Conferences at New Prairie Press. It has been accepted for inclusion in Conference on Applied Statistics in Agriculture by an authorized administrator of New Prairie Press. For more information, please contact cads@k-state.edu. 


\section{Author Information}

Jixiang Wu, Johnie N. Jenkins, Jack McCarty Jr, and Chris Cheatham 


\title{
SEPARATION OF SINGLE GENE EFFECTS FROM ADDITIVE-DOMINANCE GENETIC MODELS
}

\author{
Jixiang $\mathrm{Wu}^{1,3}$, Johnie N. Jenkins ${ }^{2 *}$, Jack McCarty $\mathrm{Jr}^{2}{ }^{2}$, Chris Cheatham ${ }^{1}$ \\ ${ }^{1}$ Department of Plant and Soil Sciences, Mississippi State University, ${ }^{2}$ Crop Science \\ Research Laboratory, USDA-ARS, Mississippi State, MS, and ${ }^{3}$ College of Agriculture \& \\ Biotechnology, Zhejiang University, Zhejiang
}

\begin{abstract}
Separation of single gene and polygenic effects would be useful in crop improvement. In this study, additive-dominance model with a single qualitative gene based on diallel crosses of parents and progeny $F_{1} \mathrm{~s}$ (or $F_{2} \mathrm{~s}$ ) was examined. The mixed linear model approach, minimum norm quadratic unbiased estimation (MINQUE), was used to estimate the variance and covariance components and single gene effects. Monte Carlo simulation was used to evaluate the efficiency of each parameter estimated from the MINQUE approach for this genetic model. The results of 200 simulations indicated that estimates of variance components and single gene effects were unbiased when setting different single gene effects for parents and $F_{1} \mathrm{~s}$ (or $F_{2} \mathrm{~s}$ ). Results also indicated that estimates of variances and single gene effects were very similar for both genetic populations. Therefore, single gene effects could be effectively separated and estimated by this approach. This research should aid the extension of this model to cases that involve multiple linked or unlinked genes (or genetic markers) and other complex ploygenic models. For illustration, a real data set comprised of eight parents of upland cotton (Gossypium hirsutum L.) with normal leaf and one parent with okra leaf, and their $44 F_{2} \mathrm{~s}$ were used to estimate the variance components and the genetic effects of the okra leaf gene on fiber traits.
\end{abstract}

Keywords: mixed linear model, qualitative gene effects, polygenic effects, Monte Carlo simulation, variance components

\section{Introduction}

Quantitative traits like plant height and product yield are expressed continuously and controlled by polygenic effects. However, qualitative genes that determine seed coat color, leaf shape, and other qualitative traits may also affect the genetic expression of quantitative traits (Sax, 1923; McMillan and Robertson, 1974; Wexelsen, 1932). Therefore, separation of qualitative gene effects and polygenic effects would be useful in crop improvement. The relationship between quantitative trait loci (QTLs) and qualitative genes (or markers) can be evaluated using statistical methods (Weller, 1986; Paterson et al., 1988; Lander and Botstein, 1989; Zeng, 1994; Zhu, 1998) if markers and linkage maps are available for a large mapping population. It would be difficult, however, to detect effects on quantitative characters using 
QTL-mapping approaches if there were only a few qualitative genes or morphological markers or if linkage maps are unavailable.

Methods for specific genes that affect quantitative traits were reviewed by Thompson and Thoday (1979). Theoretical aspects of these methods have been discussed previously (Elston and Steward, 1973; Hill, 1975; Jayakar, 1970; Soller et al., 1976 and 1979). Several studies have reported on the use of these methodes in agricultural species (Tanksley et al., 1982; Zhuchenko et al., 1979). Tan and D'Angelo (1979), Elston and Stewart (1973), Elston (1984), Tan and Chang (1972), Jiang et al. (1994) proposed several genetic models involving polygenes and or/and major genes with mixture models. However, all of these genetic models and corresponding methods of analysis utilize only two inbred lines and their progenies. The limitations of these methods are: 1) the inability to analyze combined data of multiple inbred lines and their progenies, and 2) difficulty of including GXE interaction models. Gilbert (1985a) extended Hayman's (1954) model and was able to analyze single gene effects and polygenic effects simultaneously. He also compared the statistical properties of five experimental methods, of which, the diallel method provided the most information on genetic components of variation (Gilbert, 1985b). This method was easily analyzed by the Analysis of Variance (ANOVA) methodology approaches; however, it utilized inbred lines and their $\mathrm{F}_{1}$ single crosses. This method is not easily extended to other generations such as $\mathrm{F}_{2}$ and $\mathrm{BC}$.

With the development of mixed linear model approaches, many genetic models and flexible statistical methods have been proposed for analyzing quantitative traits. Examples include additive-dominance (AD) models, additive-dominance maternal (ADM) models, additivedominance additive $\times$ additive epistasis (ADAA) models and other genetic models based on balanced or unbalanced diallel crosses for different generations (Cockerham, 1980; Zhu, 1994). Utilizing a mixed linear model approach, we extended the additive-dominance genetic model for diallel crosses of parents and $\mathrm{F}_{1} \mathrm{~s}$ (or $\mathrm{F}_{2} \mathrm{~s}$ ) with one qualitative gene (or marker) with two alleles. Monte Carlo simulation was used to evaluate the power and unbiasedness of estimated variance components and single gene effects from MINQUE approach. An example illustrates the estimation of the variance components and the genetic effects of the okra leaf gene on several fiber traits.

\section{Genetic Models and Methodology}

It was assumed that the qualitative gene was single and co-dominant (or dominant) with normal segregation in segregating generations from diploid inbred lines, total genetic effect includes qualitative gene additive (T) and dominant effects $(\mathrm{S})$, polygene additive (A) and dominance (D) (Gilbert, 1985a) effects without GXE interaction, and that single gene effects were independent of polygenic effects.

For a diallel mating design (Griffing, 1956; Hallauer and Miranda, 1981), the mean performance of an $F_{1}$ from parents $i$ and $j$ in block $k$ can be expressed by the following linear models:

$$
\begin{aligned}
& y_{t i j k\left(I_{i}\right)}=\mu+T_{t}+A_{i}+A_{j}+D_{i j}+B_{k}+e_{t i j k k}(1) \text { if alleles } t \text { and } t^{\prime} \text { are same, and } \\
& y_{t t^{\prime} j k\left(F_{i}\right)}=\mu+S_{t t^{\prime}}+A_{i}+A_{j}+D_{i j}+B_{k}+e_{t t^{\prime} j k} \text { (2)if alleles } t \text { and } t^{\prime} \text { are different. }
\end{aligned}
$$


The selfed progeny of $F_{1}$ (i.e.) can be expressed as the following models:

$$
y_{t t^{\prime} j k\left(F_{2}\right)}=\mu+T_{t}+A_{i}+A_{j}+\frac{1}{4} D_{i i}+\frac{1}{4} D_{j j}+\frac{1}{2} D_{i j}+B_{k}+e_{t^{\prime} t i j k} \text { (3) if alleles } t \text { and } t^{\prime} \text { are same, }
$$

and $y_{t t^{\prime} j k\left(F_{2}\right)}=\mu+\frac{1}{2} S_{t t^{\prime}}+A_{i}+A_{j}+\frac{1}{4} D_{i i}+\frac{1}{4} D_{j j}+\frac{1}{2} D_{i j}+B_{k}+e_{t^{\prime} t j k}$ (4) if alleles $t$ and $t^{\prime}$ are different.

The performance of parent $i$ can be expressed by the linear model, $y_{\text {tilik }}=\mu+T_{t}+2 A_{i}+D_{i i}+B_{k}+e_{t i t i k}(5)$

where, $\mu$ is the population mean, fixed effect;

$T_{t}$ is the additive effect for allele $t$ of the single qualitative gene, fixed effect, $\sum_{t=1}^{2} T_{t}=0$;

$S_{t t^{\prime}}$ is the heterozygous single qualitative gene dominance effect for alleles $t$ and $t^{\prime}$, fixed effect, assuming homozygous dominance effect $S_{t t}=0$;

$A_{i}\left(\right.$ or $\left.A_{j}\right)$ is additive effect from parent $i$ (or $j$ ), $A_{i}$ or $A_{j} \sim N\left(0, \sigma_{A}^{2}\right)$;

$D_{i i}, D_{j j}$, or $D_{i j}$ is the dominance effect of alleles from parents $i$ and $j$ parents $, D_{i i}, D_{j j}$, or $D_{i j} \sim N\left(0, \sigma_{D}^{2}\right)$;

$B_{k}$ is the block effect with $B_{k} \sim N\left(0, \sigma_{B}^{2}\right)$;

$e_{t t^{\prime} i j k}$ is the random error with $e_{t t^{\prime} j j k} \sim N\left(0, \sigma_{e}^{2}\right)$.

These mixed linear models can be expressed in matrix notation form as follows,

$$
\begin{aligned}
\mathbf{y} & =\mathbf{1} \mu+\mathbf{X}_{T} \mathbf{b}_{T}+\mathbf{X}_{S} \mathbf{b}_{S}+\mathbf{U}_{A} \mathbf{e}_{A}+\mathbf{U}_{D} \mathbf{e}_{D}+\mathbf{U}_{B} \mathbf{e}_{B}+\mathbf{e}_{e} \\
& =\sum_{i=1}^{3} \mathbf{X}_{i} \mathbf{b}_{i}+\sum_{u=1}^{4} \mathbf{U}_{u} \mathbf{e}_{u} \\
& =\mathbf{X b}+\mathbf{U} \mathbf{e}
\end{aligned}
$$

where, $\mathbf{y}$ is the vector of observed values, $\mathbf{1}$ is a vector in which each element is one, $\mathbf{X}_{T}$ and $\mathbf{X}_{S}$ are known information matrices for fixed effect vectors of additive ( $\left.\mathbf{b}_{T}\right)$ and heterozygous dominance $\left(\mathbf{b}_{S}\right)$ effects of single qualitative gene, $\mathbf{U}_{A}$ and $\mathbf{U}_{D}$ are the known information matrices for random effect vectors of additive $\left(\mathbf{e}_{A}\right)$ and dominance $\left(\mathbf{e}_{l}\right)$ effects of polygenetic genes, $\mathbf{U}_{B}$ is the known information matrix for random effect vectors of block $\left(\mathbf{e}_{B}\right)$.

The total phenotype variance $V_{P}$ for each trait can be partitioned as the follows:

$$
V_{P}=V_{A}+V_{D}+V_{e}
$$

where, $V_{A}, V_{D}$, and $V_{e}$ are the variance components of additive, dominance, and random error, respectively. The minimum generations of this model required are parents and $F_{1} \mathrm{~s}$ (or parents and $F_{2}$ s).

Traditional ANOVA approaches could be used to estimate the variance components and qualitative gene effects for balanced data of diallel crosses of parents and $F_{1} \mathrm{~s}$ (Gilbert, 1985a); however, ANOVA approaches can not be used for genetic populations where one or more crosses are missing or for populations containing $F_{2}$ progenies because coefficients for 
dominance effects for both single gene and polygenic genes are non-integer for the $F_{2}$ generation. Maximum Likelihood (ML) could be used to estimate the variance components and fixed effects (Hartley and Rao 1967) for unbalanced data cases; however, this method is iterative and the estimates are influenced by the fixed effect $\mathbf{b}$. Consequently, estimates of variance components may be biased. Restricted Maximum Likelihood (REML) (Patterson and Thompson, 1971) approaches could also be used to estimate the variance components and single gene effects, but this method is also iterative and time-consuming. In this study, the MINQUE approach was used to estimate variance components (Rao, 1971; Zhu, 1989). The fixed effects are estimated by generalized least square estimation method (Neter, et al., 1985),

$$
\hat{\mathbf{b}}=\left(\mathbf{X}^{T} \mathbf{V}^{-1} \mathbf{X}\right)^{-1} \mathbf{X}^{T} \mathbf{V}^{-1} \mathbf{y}
$$

where, $\mathbf{X}$ is the known information matrix of unknown fixed effect vector $\mathbf{b}$, $\mathbf{V}=\sum_{u=1}^{3} \sigma_{u}^{2} \mathbf{U}_{u} \mathbf{U}_{u}^{T}+\sigma_{e}^{2} \mathbf{I}$ with inverse matrix $\mathbf{V}^{-1}, \mathbf{y}$ is the vector of observed value. Adjusted unbiased prediction (AUP) (Zhu, 1993) or linear unbiased prediction (LUP) (Zhu and Weir, 1994) approach could be used to predict the random effects. Since the power of the z-test for significance of variance components was very low, the jackknifing resampling approach by removing one block at a time was used to estimate the each parameter and its standard error. The $t$ test was next used to test the significance of each parameter (Miller, 1974; Zhu, 1993).

\section{Monte Carlo Simulation}

In these simulations, we set six parents with positive qualitative gene additive effects ( $S=0$, 10, and 20) and two parents with negative qualitative gene additive effects, the qualitative gene heterozygous dominance effects $\left(\mathrm{T}=0,10\right.$, and 20). Variance components were set to $\sigma_{A}^{2}=50$, $\sigma_{D}^{2}=20$, and $\sigma_{e}^{2}=5$. Next, a total of 200 simulations were conducted for each of the nine combinations of additive and dominance effects for both $\left(\mathrm{P}+F_{1}\right)$ and $\left(\mathrm{P}+F_{2}\right)$ populations to estimate the variance components and qualitative gene effects. The simulation results for variance components are summarized in Tables 1 and 2.

The estimate and the power for each variance component were similar for populations of either parents and $F_{1} \mathrm{~s}$ or parents and $F_{2} \mathrm{~s}$. Estimates of the variance components did not depend on the size of the qualitative gene effects. Therefore, if all qualitative gene effects are equal to zero, then this model can be reduced to the traditional additive-dominance (AD) model. Results in Tables 3 and 4 indicated that estimates of qualitative gene effects were unbiased for both types of populations.

\section{Worked Example}

For an illustration, an actual data set involving 10 parents of upland cotton with normal leaf and one parent with okra leaf, and their $44 F_{2}$ progenies were used to estimate the variance components and the genetic effects of the okra leaf gene on three fiber traits (micronaire, fiber elongation and fiber strength). Chi-square goodness-of-fit analysis indicated that okra leaf trait was controlled by a single and co-dominant gene (Table 6). The okra leaf gene had significant positive additive effect on fiber strength and negative additive effect on micronaire, but no significant additive effect on fiber elongation. No significant heterozygous dominant effects were 
detected for any of the three fiber traits (Table 7). The results indicated that the okra leaf gene is probably linked with the genes controlling the genetic expression of high fiber strength and fiber fineness (micronaire). This suggests that upland cotton breeding programs to develop high strength cultivars should utilize backcrossing schedule and/or indirect okra leaf shape selection.

\section{Discussion}

A morphological marker gene may control both the expression of the specific qualitative marker trait, as well as other quantitative traits. However, the traditional additive-dominance genetic models cannot separate the genetic influence of the marker from additive and dominance effects. This research extends the traditional additive-dominance model to include both singlegene and polygenic effects, using mixed linear model approaches, when a single marker with known contrasting gene types for parents and their $F_{1}$ or $F_{2}$ progenies with either balanced or unbalanced set of crosses. Estimates of fixed effects and variance components were unbiased as shown by Monte Carlo simulations for different generations. If there is no qualitative gene effect, the new model can be reduced to the traditional additive-dominance genetic model. Compared with Gilbert's (1985a) method, our methods are more flexible. The benefits of this model and statistical method of analysis include: 1) this method can contain either $F_{1}$ or $F_{2}$ progenies; and (2) the model is extendable to other complicated genetic models. With increased detection and use of molecular markers, this method provides the opportunity to include cases with multiple linked or unlinked qualitative genes (or markers). If more generations are included, the model can also be extended to other more complex polygenic models (Cockerham, 1980, Zhu, 1994). A free copy of this software written in $\mathrm{C}++$ could be obtained at our USDA-ARS research lab, Genetic and Precision Agriculture Research Unit Box 5367, Mississippi State, MS 39762.

In the example data set, we found that leaf shapes (i.e., normal and okra) of upland cotton were controlled by a single gene. The upland cotton leaf shapes will influence leaf area and photosynthesis efficiency which may then influence cotton yield or/and fiber quality. Results indicated that the okra leaf gene would improve $6 \%$ of fiber strength (T1) and reduce $5 \%$ of fiber thickness (micronaire). Combining the okra leaf gene effects with polygenic additive effects for fiber quality should aid the breeding programs in the development of high fiber quality upland cotton cultivars.

\section{Summary}

The simulation results indicated that, 1. the estimation for variance components was same when different single gene effects existed, 2. estimation of variance components was very seminar for both parents $\mathrm{P}$ and F2, and parents and F1 when different single gene effects existed, and 3. both populations can get unbiased estimation for different single gene effects. Therefore, the above results indicted that this model can be used to separate the related single gene effects from the polygenic effects by MINQUE approaches could be effectively used to estimate the polygenic variances and single gene effects unbiasedly in the genetic model. The real data analysis revealed that both okra leaf gene has significant positive additive effect on fiber strength and negative additive effects on micronaire, but no significant additive effect on fiber elongation. 
The results would be helpful for researchers to improve fiber strength efficiently in upland cotton breeding programs.

\section{Acknowledgements}

The authors wish to thank Drs C. E. Watson Jr, and J. Willers and the other reviewers for their careful reading and good suggestion of the manuscript.

\section{References}

Cockerham, C. C. 1980. Random and fixed effects in plant genetics. Theor. App.l Genet. 56:119131.

Elston, R. C. 1984. The genetic analysis of quantitative traits between two homozygous lines. Genetics 108:733-744.

Elston, R. C., and J. Stewart 1973. The analysis of quantitative traits for simple genetic models from parental, $\mathrm{F}_{1}$ and backcross data. Genetics 73:695-711.

Gilbert D.G. 1985a. Estimating single gene effects on quantitative traits. 1. A diallel method applied to Est 6 in D. melanogaster. Theor. Appl. Genet. 69:625-629.

Gilbert D.G. 1985b. Estimating single gene effects on quantitative traits. 2. Statistical properties of five experimental methods. Theor. Appl. Genet. 69: 631-636.

Griffing, B. I. 1956. Concept of general and specific combining ability in relation to diallel crossing systems. Aust. J. Biol. Sci. 9: 463-493.

Hallauer, A. R., and J. B. Miranda 1981. Quantitative Genetics in Maize Breeding. Iowa State University Press, Ames, Iowa.

Hartley, H. O., and J. N. K. Rao 1967. Maximum-likelihood estimation for the mixed analysis of variance model. Biometrika, 54: 93-108.

Hayman, B. I. 1954. The analysis of variance of diallel tables. Biometrics 10:235-244.

Hill, A.P. 1975. Quantitative linkage: A statistical procedure for its detection and estimation. Annals of Human Genetics 38:439-450.

Jayakar, S.D. 1970. On the detection and estimation of linkage between a locus influencing a quantitative character and a marker locus. Biometrics 26:451-464.

Jiang C., X. Pan, and M. Gu 1994. The use of mixture models to detect effects of major genes on quantitative characters in a plant breeding experiment. Genetics 136: 383-394.

Lander, E. S. and D. Botstein 1989. Mapping Medelian factors underlying quantitative traits using RFLP linkage maps. Genetics 121:185-199.

McMillan, I., and A. Robertson 1974. The power of methods for detection of major genes affecting quantitative characters. Heredity 32:349-356.

Miller, R. G. 1974. The jackknife: a review. Biometrika, 61: 1-15.

Neter J., W. Wasserman, and M. H. Kutner 1985. Applied Linear Statistical Models ( $2^{\text {nd }}$ edition). Richard D. Irwin, Inc.

Paterson, A. H., E. S. Lander, J. D. Hewitt, S. Peterson, S. E. Lincoln and S. D. Tanksley 1988. Resolustion of quantitative traits into Mendelian factors by using a complete RFLP linkage map. Nature 335:721-726. 
Patterson, H.D. and Thompson, R. 1971. Recovery of inter-block information when block sizes are unequal. Biometrika, 58: 545-554.

Rao, C. R. 1971. Estimation of variance and covariance components MINQUE theory. Journal of Multivariate Analysis, 1: 257-275.

Sax, K. 1923. The association of size differences with seed-coat pattern and pigmentation in Phaseolus vulgaris. Genetics 8:552-560.

Soller, M., T. Brody, and A Genizi 1976. On the power of experimental marker-linked quantitative effects in crosses between inbred lines. Theor. Appl. Genet. 47: 35-39.

Soller, M., T. Brody, and A Genizi 1979. The expected distribution of marker-linked quantitative effects in crosses between inbred lines. Heredity 43:179-190.

Tan, W.Y., and W. C. Chang 1972. Convolution approach to the genetic analysis of quantitative chararcters of self-fertilized populations. Biometrics 28: 1073-1090.

Tan, W. Y., and H. D'Angelo 1979. Statistical analysis of joint effects of major genes and polygenes in quantitative genetics. Biomet. J. 21:179-192.

Tanksley, S. D., H. Medina-Filho and C. M. Rick 1982. Use of naturally-occurring enzyme variation to detect and map genes controlling quantitative traits in an interspecific backcross of tomato. Heredity 49:11-25.

Thompson, J.N. Jr., and J.M. Thoday 1979. Quantitative genetic variation. Academic Press, Lonon,UK.

Weller, J.L. 1986. Maximum likelihood techniques for the mapping and analysius of quantitative traits loci with aid of genetic markers. Biometrics 42: 627-640

Wexelsen, H., 1932. Linkage of a quantitative and a qualitative character in barley. Hereditas 17:323-341.

Zeng, Z-B. 1994. Precision mapping of quantitative trait loci. Genetics 136: 1457-1468.

Zhu, J. 1998. Mixed model approaches of mapping genes for complex quantitative traits. p.19-20 In L. Z. Wang and J. R. Dai (ed.), Proceedings of Genetics and Crop Breeding of China.. Chinese Agricultural Science and Technology Publication House, Beijing.

Zhu, J. 1989. Estimation of genetic variance components in the general mixed model. Ph.D. Dissertation, North Carolina State University, Raleigh, U.S.A.

Zhu, J. 1993. Methods of predicting genotype value and heterosis for offspring of hybrids. (Chinese). Journal of Biomathematics (Chinese), 8(1): 32-44.

Zhu, J. 1994. General genetic models and new analysis methods for quantitative traits. (Chinese). Journal of Zhejiang Agricultural University, 20(6): 551-559.

Zhu, J. and B. S. Weir 1994. Analysis of cytoplasmic and maternal effects: I. a genetic model for diploid plant seeds and animals. Theor. Appl. Genet. 89:153-159.

Zhuchenko,A. A., A. P. Samovol, A. B. Korol, and V. K. Andryushchenko, 1979. Linkage between loci of quantitative characters and marker loci, II. Influence of three tomato chromosomes on variability of five quantitative characters in backcross progenies. Genetika 15:672-683. 
Table 1. Estimation of each variance component and testing power based on parents and $F_{1}$.

\begin{tabular}{lrrrrrrr}
\hline & \multicolumn{2}{c}{$\mathrm{S}=0$} & \multicolumn{2}{c}{$\mathrm{S}=10$} & \multicolumn{2}{c}{$\mathrm{S}=20$} \\
\cline { 2 - 8 } Parameter & Est. & Power $^{*}$ & Est. & Power & Est. & Power \\
\hline$\sigma_{A}^{2}=50$ & $\mathrm{~T}=0$ & 53.02 & 1.00 & 53.02 & 1.00 & 53.02 & 1.00 \\
$\sigma_{D}^{2}=20$ & & 19.57 & 1.00 & 19.57 & 1.00 & 19.57 & 1.00 \\
$\sigma_{e}^{2}=5$ & 5.09 & 0.98 & 5.09 & 0.98 & 5.09 & 0.98 \\
& & & & & & & \\
\hline$\sigma_{A}^{2}=50$ & & 53.01 & 1.00 & 53.01 & 1.00 & 53.02 & 1.00 \\
$\sigma_{D}^{2}=20$ & $\mathrm{~T}=10$ & 19.57 & 1.00 & 19.57 & 1.00 & 19.57 & 1.00 \\
$\sigma_{e}^{2}=5$ & & 5.09 & 0.98 & 5.09 & 0.98 & 5.09 & 0.98 \\
& & & & & & & \\
$\sigma_{A}^{2}=50$ & & 53.01 & 1.00 & 53.02 & 1.00 & 53.02 & 1.00 \\
$\sigma_{D}^{2}=20$ & $\mathrm{~T}=20$ & 19.57 & 1.00 & 19.57 & 1.00 & 19.57 & 1.00 \\
$\sigma_{e}^{2}=5$ & & 5.09 & 0.98 & 5.09 & 0.98 & 5.09 & 0.98 \\
\hline
\end{tabular}

$\mathrm{T}$ and $\mathrm{S}$ are the additive and dominance effect, respectively

*: Significant at $5 \%$ level or less

Table 2. Estimation of each variance component and testing power based on parents and $F_{2}$.

\begin{tabular}{|c|c|c|c|c|c|c|c|}
\hline & & \multicolumn{3}{|c|}{$\mathrm{S}=0$} & \multicolumn{2}{|l|}{$S=10$} & $S=20$ \\
\hline \multicolumn{2}{|c|}{ Parameters } & Est. & Power & Est. & Power & Est. & Power \\
\hline$\sigma_{A}^{2}=50$ & $\mathrm{~T}=0$ & 53.18 & 1.00 & 53.18 & 1.00 & 53.18 & 1.00 \\
\hline$\sigma_{D}^{2}=20$ & & 19.56 & 0.79 & 19.56 & 0.79 & 19.56 & 0.79 \\
\hline$\sigma_{e}^{2}=5$ & & 5.09 & 0.98 & 5.09 & 0.98 & 5.09 & 0.98 \\
\hline$\sigma_{A}^{2}=50$ & & 53.18 & 1.00 & 53.18 & 1.00 & 53.18 & 1.00 \\
\hline$\sigma_{D}^{2}=20$ & $\mathrm{~T}=10$ & 19.56 & 0.79 & 19.56 & 0.79 & 19.56 & 0.79 \\
\hline$\sigma_{e}^{2}=5$ & & 5.09 & 0.98 & 5.09 & 0.98 & 5.09 & 0.98 \\
\hline$\sigma_{A}^{2}=50$ & & 53.18 & 1.00 & 53.18 & 1.00 & 53.18 & 1.00 \\
\hline$\sigma_{I)}^{2}=20$ & $\mathrm{~T}=20$ & 19.56 & 0.79 & 19.56 & 0.79 & 19.56 & 0.79 \\
\hline$\sigma_{e}^{2}=5$ & & 5.09 & 0.98 & 5.09 & 0.98 & 5.09 & 0.98 \\
\hline
\end{tabular}

$\mathrm{T}$ and $\mathrm{S}$ are the additive and dominance effect, respectively 
Table 3. Estimation of major gene effects component and testing power based on parents and $F_{1}$.

\begin{tabular}{cccccccc}
\hline & & \multicolumn{2}{c}{$\mathrm{S}=0$} & \multicolumn{2}{c}{$\mathrm{S}=10$} & \multicolumn{2}{c}{$\mathrm{S}=20$} \\
\cline { 3 - 7 } & & & & & & & \\
$\mathrm{T}$ & $\mathrm{Est.}$ & Power & Est. & Power & Est. & Power \\
$\mathrm{S}$ & & 0.03 & --- & 0.03 & -- & 0.03 & --- \\
& & 0.01 & --- & 10.01 & 1.00 & 20.01 & 1.00 \\
\cline { 1 - 4 } $\mathrm{T}$ & $\mathrm{T}=10$ & 10.03 & 0.98 & 10.03 & 0.98 & 10.03 & 0.98 \\
$\mathrm{~S}$ & & 0.01 & --- & 10.01 & 1.00 & 20.01 & 1.00 \\
& & & & & & & \\
$\mathrm{~T}$ & $\mathrm{~T}=20$ & 20.03 & 1.00 & 20.03 & 1.00 & 20.03 & 1.00 \\
$\mathrm{~S}$ & & 0.01 & --- & 10.01 & 1.00 & 20.01 & 1.00 \\
\hline
\end{tabular}

$\mathrm{T}$ and $\mathrm{S}$ are the additive and dominance effect, respectively

Table 4. Estimation of major gene effects and testing power based on parents and $F_{2}$.

\begin{tabular}{|c|c|c|c|c|c|c|c|}
\hline \multirow[b]{2}{*}{ Parameters } & & \multicolumn{2}{|c|}{$S=0$} & \multicolumn{2}{|c|}{$\mathrm{S}=10$} & \multicolumn{2}{|c|}{$\mathrm{S}=20$} \\
\hline & & Est. & Power & Est. & Power & Est. & Power \\
\hline $\mathrm{T}$ & $\mathrm{T}=0$ & 0.04 & --- & 0.04 & --- & 0.04 & -- \\
\hline S & & -0.04 & --- & 9.96 & 1.00 & 19.96 & 1.00 \\
\hline $\mathrm{T}$ & $\mathrm{T}=10$ & 10.04 & 0.97 & 10.04 & 0.97 & 10.04 & 0.97 \\
\hline $\mathrm{S}$ & & -0.04 & --- & 9.96 & 1.00 & 19.96 & 1.00 \\
\hline $\mathrm{T}$ & $\mathrm{T}=20$ & 20.04 & 1.00 & 20.04 & 1.00 & 20.04 & 1.00 \\
\hline $\mathrm{S}$ & & -0.04 & --- & 9.96 & 1.00 & 19.96 & 1.00 \\
\hline
\end{tabular}

$\mathrm{T}$ and $\mathrm{S}$ are the additive and dominance effect, respectively 
Table 5. Format for real data set involving 9 parents and $44 F_{2}$ hybrids

\begin{tabular}{llllllllll}
\hline \multicolumn{2}{c}{ Femal } & Male & & & & & \\
Env $^{\mathrm{a}} \mathrm{e}^{\mathrm{b}}$ & ${ }_{\mathrm{b}}$ & $\mathrm{T}^{\mathrm{c}}$ & $\mathrm{T}^{\mathrm{d}}$ & $\mathrm{Gen}^{\mathrm{e}}$ & $\mathrm{REP}^{\mathrm{f}}$ & Mic $^{\mathrm{g}}$ & Elong $^{\mathrm{g}}$ & $\mathrm{T}^{\mathrm{g}}$ \\
\hline 1 & 1 & 1 & 1 & 1 & 0 & 1 & 5 & 8.75 & 19.15 \\
1 & 1 & 2 & 1 & 1 & 2 & 1 & 4.6 & 7.75 & 19.55 \\
1 & 1 & 3 & 1 & 2 & 2 & 1 & 4.1 & 7 & 21.2 \\
$\ldots$ & $\ldots$ & $\ldots$ & $\ldots$ & $\ldots$ & $\ldots$ & $\ldots$ & $\ldots$ & $\ldots$ & $\ldots$ \\
1 & 2 & 3 & 1 & 2 & 2 & 1 & 4.6 & 7.25 & 20.85 \\
1 & 2 & 4 & 1 & 1 & 2 & 1 & 4.8 & 6.75 & 21.25 \\
1 & 2 & 8 & 1 & 1 & 2 & 1 & 4.8 & 6.75 & 22.8 \\
1 & 2 & 9 & 1 & 1 & 2 & 1 & 4.5 & 6.5 & 22.7 \\
1 & 3 & 3 & 2 & 2 & 0 & 1 & 4.2 & 7.25 & 23.45 \\
1 & 3 & 8 & 2 & 1 & 2 & 1 & 4.4 & 6.5 & 22.3 \\
1 & 3 & 9 & 2 & 1 & 2 & 1 & 4.3 & 6.75 & 24.55 \\
$\ldots$ & $\ldots$ & $\ldots$ & $\ldots$ & $\ldots$ & $\ldots$ & $\ldots$ & $\ldots$ & $\ldots$ & $\ldots$ \\
1 & 4 & 3 & 1 & 2 & 2 & 1 & 4.7 & 6.25 & 22.95 \\
1 & 9 & 8 & 1 & 1 & 2 & 1 & 4.4 & 5.75 & 25.1 \\
1 & 9 & 9 & 1 & 1 & 0 & 1 & 4.5 & 6.5 & 23.6 \\
$\ldots$ & $\ldots$ & $\ldots$ & $\ldots$ & $\ldots$ & $\ldots$ & $\ldots$ & $\ldots$ & $\ldots$ & $\ldots$ \\
1 & 1 & 1 & 1 & 1 & 0 & 4 & 5 & 7.25 & 18.8 \\
1 & 1 & 2 & 1 & 1 & 2 & 4 & 4.5 & 7 & 19.85 \\
1 & 1 & 3 & 1 & 2 & 2 & 4 & 4.3 & 7.5 & 22.65 \\
1 & 1 & 4 & 1 & 1 & 2 & 4 & 4.8 & 6.75 & 20.95 \\
$\ldots$ & $\ldots$ & $\ldots$ & $\ldots$ & $\ldots$ & $\ldots$ & $\ldots$ & $\ldots$ & $\ldots$ & $\ldots$ \\
1 & 9 & 9 & 1 & 1 & 0 & 4 & 4.6 & 7 & 24.5 \\
\hline
\end{tabular}

Note: $a=$ environmental code; $b=$ parental code; $c=$ qualitative gene code for female parent (1 for normal leaf and 2 for okra leaf); $d=$ qualitative gene code for male parent ( 1 for normal leaf and 2 for okra leaf); e=generation code ( 0 for parent, 1 for $F_{1}$, and 2 for $F_{2}$ ); $\mathrm{f}=$ replication code; $\mathrm{g}=$ trait 
Table 6. Chi-square values and probability values for eight crosses of upland cotton

\begin{tabular}{|c|c|c|}
\hline Crosses & $X^{2}$ value & P_value \\
\hline DP5O X FM832 & 0.348 & 0.596 \\
\hline PM1560 X FM832 & 0.192 & 0.464 \\
\hline FM975 X FM832 & 0.187 & 0.459 \\
\hline FM832 X T239 & 0.208 & 0.481 \\
\hline ST474 X FM832 & 0.251 & 0.521 \\
\hline DP90 X FM832 & 0.288 & 0.552 \\
\hline SG501 X FM832 & 0.255 & 0.525 \\
\hline FM832 X T1388 & 0.484 & 0.675 \\
\hline
\end{tabular}

Note: $\mathrm{a}=$ parent with okra leaf gene

Table 7. Estimates of okra leaf gene effects for three fiber properties

\begin{tabular}{llll}
\hline Traits & Additive & Dominance & Population mean \\
\hline Micronaire (MIC) & $-0.238^{*}$ & -0.025 & 4.70 \\
Elongation (EL) (\%) & -0.114 & -0.234 & 6.92 \\
Strength (T1) (g/tex) & $1.349^{*}$ & 0.044 & 22.97 \\
\hline
\end{tabular}

* significance at probability 0.05 . 